\title{
System dynamic model and charging control of lead-acid battery for stand-alone solar PV system
}

\author{
B.J. Huang *, P.C. Hsu, M.S. Wu, P.Y. Ho \\ New Energy Center, Department of Mechanical Engineering, National Taiwan University, Taipei, Taiwan
}

Received 17 May 2009; received in revised form 17 February 2010; accepted 18 February 2010

Available online 15 March 2010

Communicated by: Associate Editor Arturo Morales-Acevedo

\begin{abstract}
The lead-acid battery which is widely used in stand-alone solar system is easily damaged by a poor charging control which causes overcharging. The battery charging control is thus usually designed to stop charging after the overcharge point. This will reduce the storage energy capacity and reduce the service time in electricity supply. The design of charging control system however requires a good understanding of the system dynamic behaviour of the battery first. In the present study, a first-order system dynamics model of lead-acid battery at different operating points near the overcharge voltage was derived experimentally, from which a charging control system based on PI algorithm was developed using PWM charging technique.

The feedback control system for battery charging after the overcharge point ( $14 \mathrm{~V})$ was designed to compromise between the set-point response and the disturbance rejection. The experimental results show that the control system can suppress the battery voltage overshoot within $0.1 \mathrm{~V}$ when the solar irradiation is suddenly changed from 337 to $843 \mathrm{~W} / \mathrm{m}^{2}$. A long-term outdoor test for a solar LED lighting system shows that the battery voltage never exceeded $14.1 \mathrm{~V}$ for the set point $14 \mathrm{~V}$ and the control system can prevent the battery from overcharging. The test result also indicates that the control system is able to increase the charged energy by $78 \%$, as compared to the case that the charging stops after the overcharge point $(14 \mathrm{~V})$.
\end{abstract}

(C) 2010 Elsevier Ltd. All rights reserved.

Keywords: Stand-alone solar system; Battery charge control; Lead-acid battery modelling; Dynamic modelling of battery

\section{Introduction}

The stand-alone solar-powered system is widely used in remote areas where the grid power cannot reach. Therefore, durability and reliability are the two key issues.

The lead-acid battery is widely used in the stand-alone solar PV system (Jossen et al., 2004) which requires high system reliability and long service time. The lead-acid battery can easily be damaged by a poor charging control which causes overcharging. To avoid overcharge, the battery charging control is usually designed to stop charging at the overcharge point, not to complete a full-capacity

\footnotetext{
* Corresponding author.

E-mail address: bjhuang@seed.net.tw (B.J. Huang).
}

charge. This will reduce the storage energy capacity and reduce the service time in electricity supply. A good battery charging control is thus needed in order to continue charging after the overcharge point without damaging the battery. This however requires a good understanding of the system dynamic behaviour of the battery first.

In the present study, a system dynamics model of leadacid battery was derived experimentally, from which a charging control system was developed using PWM charging technique. An outdoor field test for a solar-powered LED lighting system was then carried out to verify the design of the charging control system.

To charge the battery to its full capacity, a three-stage charge algorithm can be utilized (Fig. 1). Phase 1 is to directly charge the battery from solar PV until the battery voltage reaches its overcharge point. Usually, the battery is 


\section{Nomenclature}

$C(s) \quad$ dynamic model of controller

$D_{u t y}$ duty-cycle of the PWM in charge control system

$e \quad$ control error

$I_{P V} \quad$ PV current, A

$I_{S C} \quad$ PV short circuit current, A

$I_{\text {steady }}$ steady current to battery, A

$\tilde{I}_{B} \quad$ perturbed battery charge current $\equiv I_{B}(t)-\tilde{I}_{B}, \mathrm{~A}$

$k$ a parameter in the perturbed dynamic model of battery

$K_{P} \quad$ proportional constant of the PI controller

$p \quad$ a parameter in the dynamic model of battery

$P_{V}(s) \quad$ dynamic model of PV

$P_{M A X} \quad$ MPP power of $\mathrm{PV}, \mathrm{W}$

$\tilde{R}_{B}(s)$ perturbed dynamic model of the battery $\equiv \tilde{V}_{B}(s) / \tilde{I}_{B}(s)$

$s \quad$ Laplace transform complex variable

$S_{o} \quad$ solar radiation intensity, $\mathrm{W} / \mathrm{m}^{2}$

$S_{S o}^{T} \quad$ feedback system sensitivity function
$T_{I} \quad$ integral parameter of the controller

$T_{(s)} \quad$ transfer function of the feedback control system

$V_{o} \quad$ overcharge voltage of controller, $\mathrm{V}$

$V_{B} \quad$ voltage of battery, $\mathrm{V}$

$\tilde{V}_{B} \quad$ perturbed battery voltage $\equiv V_{B}(t)-\bar{V}_{B}(s), \mathrm{V}$

$V_{O C} \quad$ open circuit voltage, $\mathrm{V}$

$V_{P M} \quad$ MPP voltage of PV, $\mathrm{V}$

$I_{P M} \quad$ MPP current of PV, A

\section{Subscripts/symbols}

IAE absolute value of the error

MPP maximum-power-point

MPPT maximum-power-point-tracking controller

nMPPO near-maximum-power-point-operation

PWM pulse width modulation

PV photovoltaic

SOC state of charge in battery

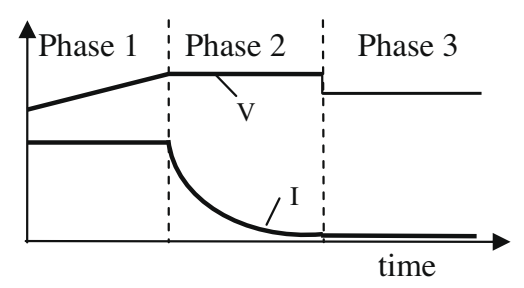

Fig. 1. Battery charging process.

charged in full load without controlling the charging current in Phase 1. Thus, only 50-80\% state of charge (SOC) can be achieved at Phase 1 . Phase 2 is to maintain the battery voltage at the overcharge point to replenish the remaining capacity. Phase 3 is to reduce the charge voltage to avoid overcharge and maintain $100 \%$ SOC for the battery. In both Phase 2 and Phase 3 the charging current generated from PV needs to be reduced in order to maintain at a set voltage. A feedback control system based on the system dynamics model of battery was then developed using pulse width modulation (PWM) technique to control the charging current from PV in Phase 2 and Phase 3.

A feedback control system as shown in Fig. 2 is developed using a PWM technique to regulate the charging current and fix the battery voltage after the overcharge point $V_{o}$. A metal-oxide-semiconductor-field-effect transistor (MOSFET) is used to switch the charging current (on/off) from solar PV via a PWM signal. The mean charging current after the overcharge point thus can be controlled by regulating the duty-cycle $D_{u t y}$ in order to fix the battery voltage at the overcharge point. The controller $C(s)$ can be properly designed with robust properties to prevent overcharging if the system dynamics model of the $P V, P_{V}$ $(s)$, and the battery $R_{B}(s)$ are known.

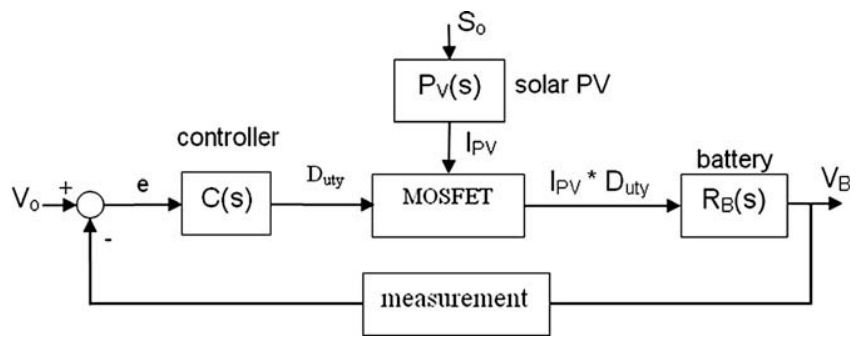

Fig. 2. Battery charging control system.

\section{Derivation of system dynamic model of a lead-acid battery}

The lead-acid performance can be modelled according to chemical (Shepherd, 1965; Kim and Hong, 1999) or combined physical and chemical model (Ekdunge, 1993; Mauracher and Karden, 1997; Buller et al., 2003; Thele et al., 2006; Sabatier, 2006). Although each model can accurately predict the battery performance, the models are non-linear and too sophisticated to be built in the microprocessor for application.

Mauracher and Karden(1997) have theoretically derived a non-linear dynamics model of lead-acid battery based on a simplified Randles' equivalent circuit. The non-linear dependence of all equivalent circuit elements on current and frequency is taken into account. Model parameters are determined by impedance spectroscopy with various superimposed direct currents. The derived model however is a high-order model resulting mainly from the equivalent electric circuit of the serial RC-connection used for the approximation of the Warburg impedance. Buller et al. (2003) further simplified the dynamic model of lead-acid battery by interpreting the impedance data in terms of 
equivalent circuit models. Both dynamic models (Mauracher and Karden, 1997; Buller et al., 2003) are however non-linear and in high order which will be difficult to be implemented in the design of a control system.

A third-order linear dynamic model of lead-acid batteries, based on an electrical model, was derived by Ceraolo (2000). The model parameters were however calculated from the given physical and chemical properties.

In the present study, a simple linear model to accurately represent the battery's dynamics behaviour near the overcharge point is derived. All the model parameters were determined using the experimental results of dynamic tests. We focus on the charging control of battery in Phase 2 at overcharge voltage $V_{o}$. Hence, a simple linear dynamic model can be derived experimentally at $V_{o}$.

A YUASA-NP 38-12 valve-regulated lead-acid (VRLA) battery $(12 \mathrm{~V}, 38 \mathrm{Ah})$ was selected in the present study. The step response method was used to test the battery and derive the system dynamic model at various battery SOC (state of charge).

Since the dynamic model of the battery is non-linear, a linearly perturbed model, Eq. (1), is thus used in system identification at various operating points, where the perturbed variable is defined with respect to a steady-state value or operating point. Fig. 3 shows the input/output relation of the battery ( $s$ denotes complex variable in Laplace transform), where $\tilde{I}_{B}\left(\equiv I_{B}(t)-\bar{I}_{B}\right)$ is the perturbed current, and $\tilde{V}_{B}\left(\equiv V_{B}(t)-\bar{V}_{B}\right)$ is the perturbed voltage, both are defined from an equilibrium or steady-state value. $\tilde{R}_{B}$ is the perturbed model of the battery defined as Eq. (1).

$\tilde{R}_{B}=\frac{\tilde{V}_{B}}{\tilde{I}_{B}}$

By inputting a step current input to the battery and measuring the voltage response, both from a steady state, the dynamic model can be derived. Various step inputs $(18 \mathrm{~s}$ for each step) based on the operating point $(14 \mathrm{~V})$, as shown in Fig. 4, are used to test the battery. Three constant-current power supplies were used to provide three kinds of currents to the battery as the step input using a switch circuit. The voltage responses are measured as sampling rate $0.001 \mathrm{~s}$ using the PIC microprocessor with an analog-to-digital converter (ADC) and the dynamic model was analyzed using Rakes' method (Rake, 1980).

The step response tests were performed at various steady-state current levels (1-4 A) and at different SOC. The current step at $1 \mathrm{~A}$ is employed when the battery reaches the set point (operating point). Fig. 5 is the Bode plot of $\tilde{R}_{B}$ analyzed from the step test results using Rake's method (Rake, 1980) for SOC $=83 \%$ and $V_{B}=14 \mathrm{~V}$. It is

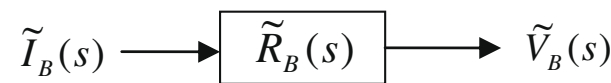

Fig. 3. Input/output model of the battery. found that the system dynamic model of the battery is the first order and can be expressed as Eq. (2):

$\tilde{R}_{B}(s)=\frac{\tilde{V}_{B}(s)}{\tilde{I}_{B}(s)}=\frac{k}{s+p}$

Table 1 lists the identified model parameters at various operating points. Fig. 6 depicts the Bode plots of the derived models at various operating points. It can be seen that the system dynamic behaviour of the battery varies with the operating points. An average model can be derived as a nominal plant model using the averaged parameters, Eq. (3).

$\tilde{R}_{B}(s)=\frac{\tilde{V}_{B}(s)}{\tilde{I}_{B}(s)}=\frac{0.0228}{s+0.0326}$

Fig. 7 is a comparison of the step response of the battery at operating point 1 and that of prediction using the average model. The real system dynamic model of the battery spans an area around the average model, which can be treated as the plant uncertainty, with respect to the average model, in feedback control system design. Thus, this average model can be used to design the feedback control system. The effect of the uncertainty of the average model on feedback system performance can be treated using a good controller design with robustness against plant uncertainty.

\section{Design and test of battery charging control system}

\subsection{System dynamic model of $P V$}

A flat-plate PV module with $2 \mathrm{X}$ reflective-type concentrator (Fig. 8) was used in the present study. The input of the PV is solar irradiation $S_{o}$ and the output is the current at a fixed PV voltage. The current response of solar PV module at the input of solar irradiation is very fast, within several milliseconds, compared to that of battery. Hence, the solar PV module can be treated as a zero-th order system with a gain only, which can be easily determined from experiment. We used an adjustable resistor as a load connected serially to the PV module and whose resistance is controlled by a microprocessor to generate different current output. By measuring the solar radiation intensity $S_{o}$ using a pyranometer, the current through the resistor, and the PV voltage, we can determine the system dynamic model of the solar PV. The solar PV module usually installs a blocking diode to avoid a reverse current through the PV at night time. Therefore, a typical $0.6 \mathrm{~V}$ forward voltage drop is then introduced when the battery is charged. The PV module was identified at set point voltage by adding the voltage drop $(0.6 \mathrm{~V})$. Fig. 9 shows the output current of the PV at different solar radiations under $V_{P V}=14.6 \mathrm{~V}$. The system dynamic model of the solar PV can be derived as:

$I_{P V}=0.00593 S_{o}-0.157$ 


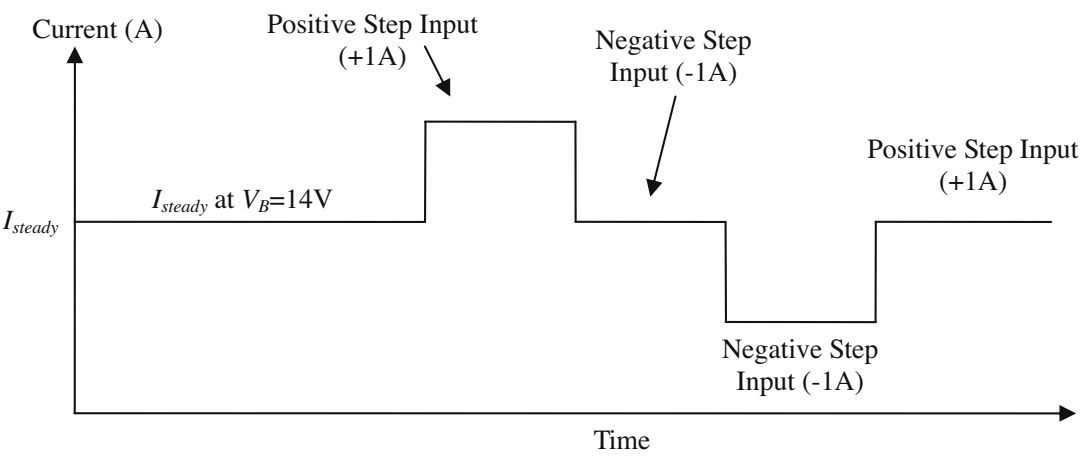

Fig. 4. Step inputs to test the battery.
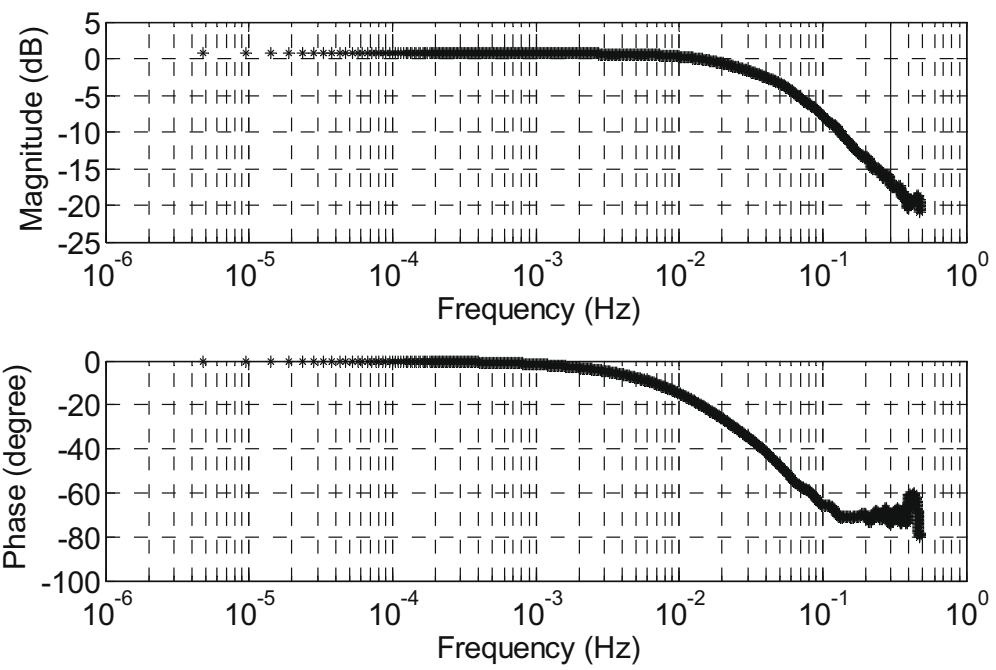

Fig. 5. Bode plot of the battery system dynamics $\left(\mathrm{SOC}=83 \%, V_{B}=14 \mathrm{~V}\right)$.

Table 1

First-order model parameters identified at different operating points.

\begin{tabular}{lllll}
\hline Operating point & SOC $(\%)$ & Step input $(\mathrm{A})$ & $k$ & $p$ \\
\hline 1 & 83 & $3 \rightarrow 4$ & 0.022 & 0.034 \\
2 & 83 & $4 \rightarrow 3$ & 0.025 & 0.0488 \\
3 & 83 & $3 \rightarrow 2$ & 0.0058 & 0.033 \\
4 & 83 & $2 \rightarrow 3$ & 0.0068 & 0.0296 \\
5 & 86 & $2 \rightarrow 3$ & 0.038 & 0.0324 \\
6 & 86 & $3 \rightarrow 2$ & 0.05 & 0.0454 \\
7 & 86 & $2 \rightarrow 1$ & 0.008 & 0.0319 \\
8 & 86 & $1 \rightarrow 2$ & 0.0067 & 0.0237 \\
9 & 91 & $1 \rightarrow 2$ & 0.0585 & 0.0434 \\
10 & 91 & $2 \rightarrow 1$ & 0.035 & 0.0272 \\
11 & 91 & $1 \rightarrow 0$ & 0.0104 & 0.0278 \\
12 & 91 & $0 \rightarrow 1$ & 0.0078 & 0.014 \\
Averaged parameters & & 0.0228 & 0.0326 \\
\hline
\end{tabular}

\subsection{Battery charging control system}

The battery overcharge point is $14.4 \mathrm{~V}$ at ambient temperature $25^{\circ} \mathrm{C}$ and it will be reduced when the ambient temperature greater than $25^{\circ} \mathrm{C}$. After taking into account the temperature coefficient (about $-15 \mathrm{mV} /{ }^{\circ} \mathrm{C}$ ), the present

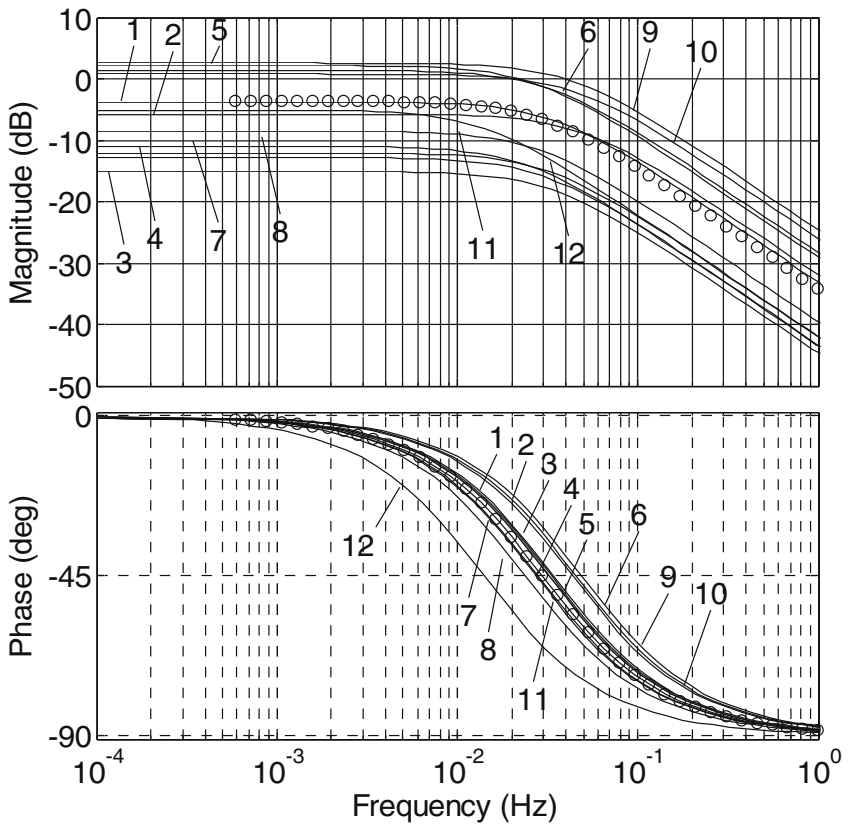

Fig. 6. Bode plots of the battery at different operating points ('o' denotes the average model). 


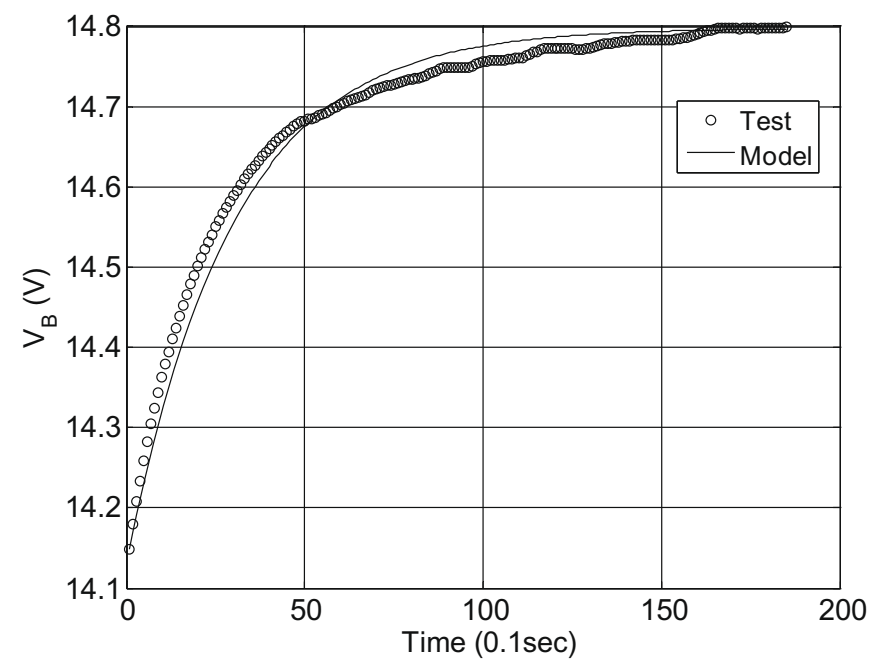

Fig. 7. The step response test data and the average model prediction at operating point 1 .

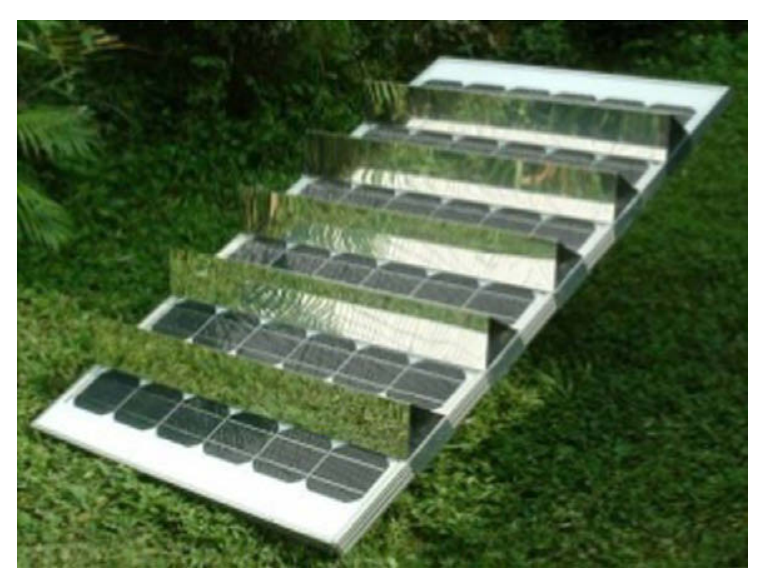

Fig. 8. Solar PV module used in the study.

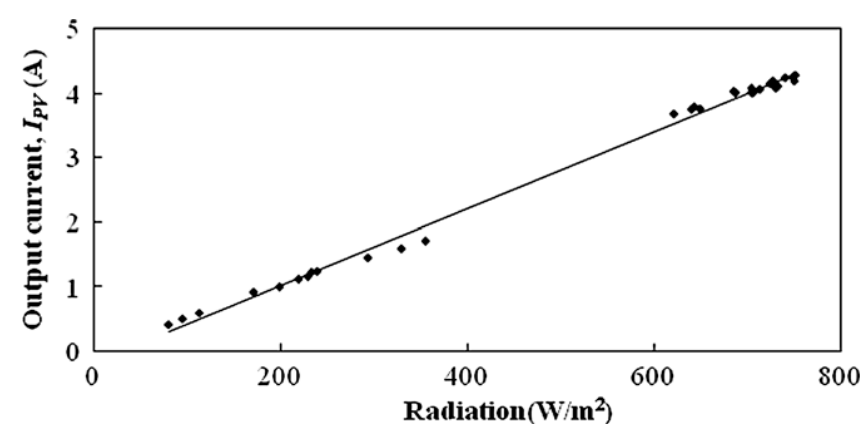

Fig. 9. System identification of the PV module at $V_{P V}=14.6 \mathrm{~V}$.

study used $14 \mathrm{~V}$ as the overcharge point in designing the PWM charging control system. The control system was designed using the sensitivity function of the feedback system to suppress the voltage overshoot when the solar radiation suddenly increases. That is, the control system has to assure that the instantaneous peak of the battery voltage due to disturbance by sudden solar radiation change will never exceed $14.4 \mathrm{~V}$, as the limiting value.
The control system design is carried out using the average model of Eq. (3) for the battery and Eq. (4) for the PV. Therefore, the control system in Fig. 2 can be expressed as Fig. 10. The uncertainty in plant dynamics is treated using the robust property of the feedback system. System simulation utilizing Simulink in MATLAB was employed to simulate the feedback system response and study the effects of disturbances and plant uncertainty.

\subsection{Controller design}

The controller design using the average model of the battery, Eq. (3), is based on PI algorithm which can have a robust property with respect to external disturbance if it was carefully tuned (Berenguel et al., 1999; Åström and Hägglund, 1995). The transfer function of the PI controller can be expressed as Eq. (5):

$C(s)=K_{P}\left(1+\frac{1}{T_{I^{s}}}\right)$

As shown in Fig. 10, the A/D converter built in the PIC microprocessor is used to measure the battery voltage for feedback. The transfer function of the closed-loop feedback control system in Fig. 10 is derived as:

$$
\begin{aligned}
T(s) & =\frac{\tilde{V}_{B}(s)}{\tilde{V}_{o}(s)} \\
& =\frac{0.0001352 K_{P}\left(T_{I} s+K_{P}\right) S_{o}}{T_{I} s^{2}+\left(0.0326+0.0001352 K_{P} S_{o}\right) T_{I} s+0.0001352 K_{P} S_{o}}
\end{aligned}
$$

The system simulation can then be carried out utilizing Simulink in MATLAB to calculate the step response of the voltage setting to determine the parameters of the controller $C(s)$, based on the set-point response.

From Routh's stability criterion, the PI controller will give a stable closed-loop system if $K_{P}>0$ and $T_{I}>0$. We define the criteria of the control system design as follows:

(1) Overshoot of set-point step response: $0 \%$ (prevent overcharging).

(2) Rise time (time for set-point step response from $10 \%$ to $90 \%)<25 \mathrm{~s}$.

(3) Settling time (time to reach $98 \%$ of the steady value) $<35 \mathrm{~s}$.

(4) Instantaneous peak battery voltage due to sudden solar radiation change: $14.4 \mathrm{~V}$.

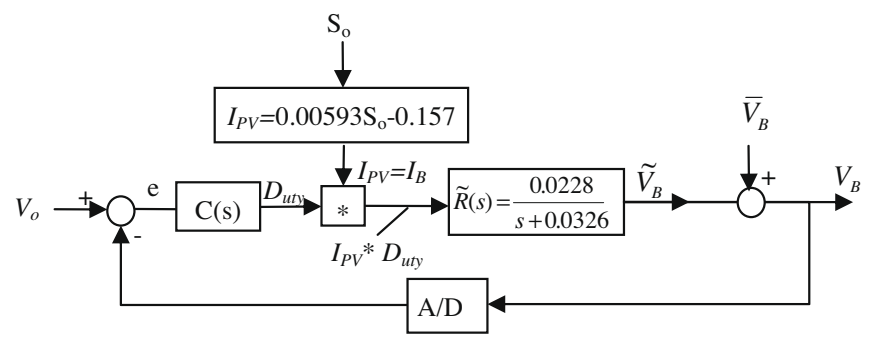

Fig. 10. Feedback control system of the solar PV battery charging. 
The simulation in use with anti-windup for integral control at saturation state shows that the effect of $K_{P}$ on control quality is not significant as $K_{P}>9$. From the time-domain simulation, the controller parameters can be determined from the integral absolute value (IAE) of the error defined in Eq. (7) which also satisfies the above control system design criteria. The resultant controller design is listed in Table 2.

$I A E=\int_{0}^{\infty}|e(t)| d t$

The controller with $K_{P}=9$ and $T_{I}=40$ seems feasible from Table 2. However, this is based on the design for set-point (battery voltage) response only. In practice, the control system will be disturbed by solar radiation change. Thus, the controller should have a property of disturbance rejection to avoid the instantaneous peak battery voltage exceeding $14.4 \mathrm{~V}$ due to sudden solar radiation increase.

The controller design is then checked using the feedback system sensitivity function, Eq. (8), to determine the proper controller parameters $T_{I}$ and $K_{p}$, which can suppress the disturbance caused by solar radiation variation and obtain a satisfactory response for the voltage set-point control to avoid overcharge.

$$
\begin{aligned}
S_{S o}^{T} & =\frac{\partial T}{\partial S_{o}} \cdot \frac{S_{o}}{T} \\
& =\frac{s^{2}+0.0326 s}{s^{2}+\left(0.0326+0.0001352 K_{P} S_{o}\right) s}+\frac{0.0326 K_{P} S_{o}}{T_{I}}
\end{aligned}
$$

It is preferable to have a lower sensitivity for the control system design in order to suppress the effect of solar radiation change, according to the sensitivity function of Eq. (8). Fig. 11 shows that the sensitivity function decreases with decreasing $T_{I}$ which will increase the overshoot in set-point response as shown in Table 2. A compromise between the set-point response and disturbance rejection thus is needed. Fig. 12 shows the variation of sensitivity function with $T_{I}$ and $K_{P}$.

A simulation using Simulink was carried out using $T_{I}=40$, which is determined from the PI controller design for set-point response at a constant solar radiation $600 \mathrm{~W} / \mathrm{m}^{2}$ (Table 2), to determine the peak voltage of battery response when solar radiation, $S_{o}$, suddenly changes from $300 \mathrm{~W} / \mathrm{m}^{2}$ to $900 \mathrm{~W} / \mathrm{m}^{2}$. The result shown in Table 3

Table 2

PI controller design for set-point response at a constant solar radiation $600 \mathrm{~W} / \mathrm{m}^{2}$.

\begin{tabular}{llllll}
\hline & Design & Design & Design & Design & Design \\
& 1 & 2 & 3 & 4 & 5 \\
\hline$T_{I}$ & 20 & 30 & 40 & 50 & 60 \\
$K_{P}$ & 5 & 7 & 9 & 11 & 13 \\
Maximum overshoot & 1.65 & 0.04 & 0 & 0 & 0 \\
$\quad(\%)$ & & & & & \\
Rise time (s) & 12 & 10.7 & 10.5 & 10.4 & 10.3 \\
Settling time (s) & 19.2 & 19.2 & 18.8 & 18.5 & 19 \\
IAE & 26.7 & 27.6 & 27.7 & 27.8 & 27.9 \\
\hline
\end{tabular}

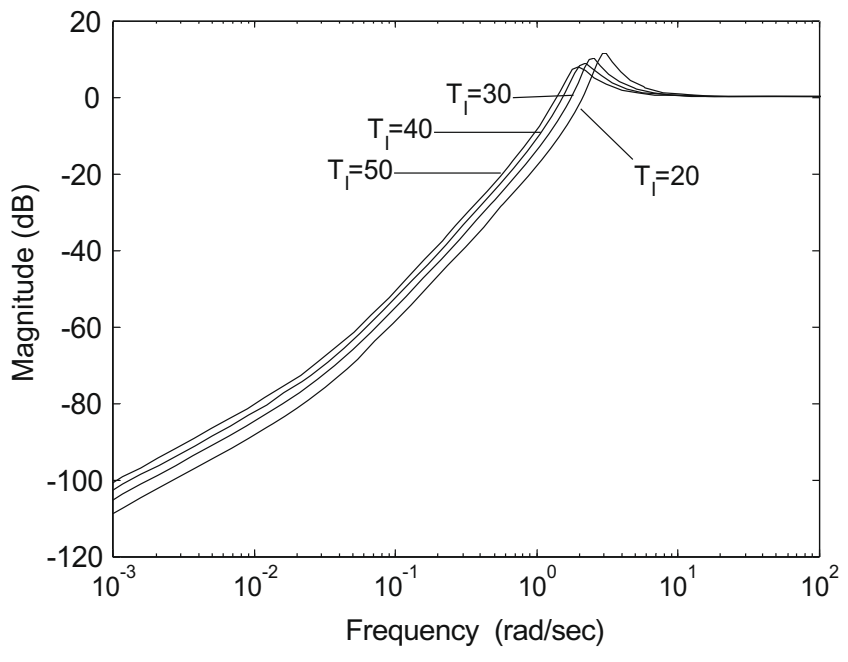

Fig. 11. The frequency response of the sensitivity function $\left(K_{P}=9\right)$.

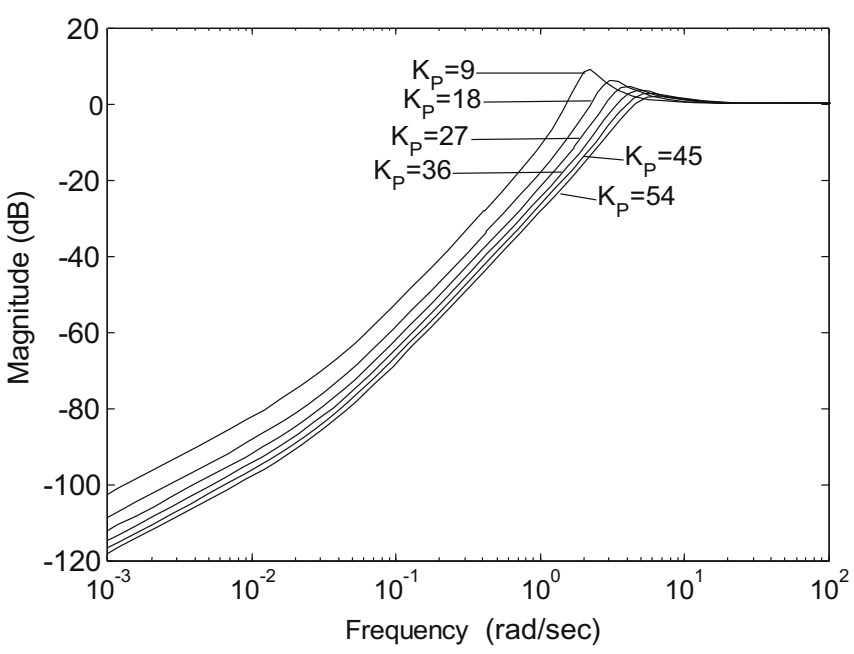

Fig. 12. The frequency response of the sensitivity function $\left(T_{I}=40\right)$.

Table 3

PI controller designs for step disturbance rejection, from $300 \mathrm{~W} / \mathrm{m}^{2}$ to $900 \mathrm{~W} / \mathrm{m}^{2}$.

\begin{tabular}{lrrrrrr}
\hline & Set 1 & Set 2 & Set 3 & Set 4 & Set 5 & Set 6 \\
\hline$T_{I}$ & 40 & 40 & 40 & 40 & 40 & 40 \\
$K_{P}$ & 9 & 18 & 27 & 36 & 45 & 54 \\
Maximum battery & 0 & 0 & 0 & 0 & 0 & 0 \\
$\quad$ voltage variation (\%) & & & & & & \\
Rise time (s) & 20.7 & 20.8 & 20.8 & 20.8 & 20.8 & 20.8 \\
Settling time (s) & 33.1 & 31.8 & 32.2 & 30.9 & 30.7 & 30.7 \\
\hline
\end{tabular}

demonstrates that the maximum voltage overshoots are approximately zero for all $K_{p}$. Fig. 13 shows that the sensitivity function decreases with increasing $K_{p}$, but the change is not obvious when $K_{P}>27$. But, higher $K_{p}$ will easily cause saturation of the controller output as well as system oscillation. Therefore, the controller design was chosen as $T_{I}=40, K_{P}=27$. The controller design for system robustness compromised between set-point response and disturbance rejection is determined as Eq. (9). 


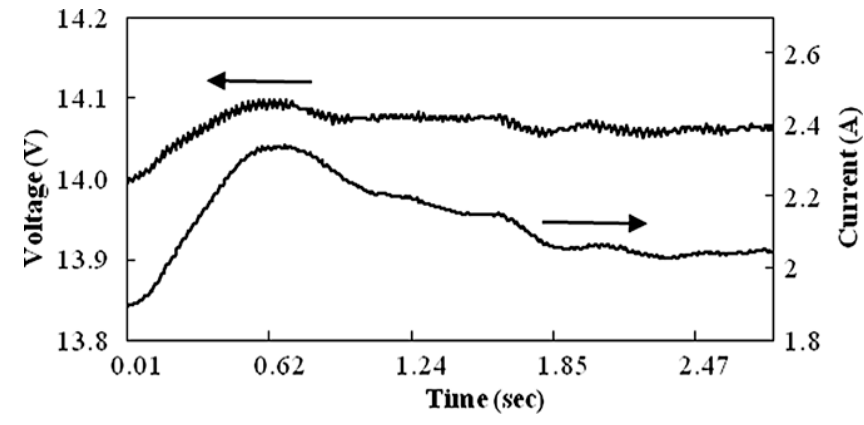

Fig. 13. Response of battery voltage at solar irradiation step change from $337 \mathrm{~W} / \mathrm{m}^{2}$ to $843 \mathrm{~W} / \mathrm{m}^{2}$.

$C(s)=27\left(1+\frac{1}{40 s}\right)$

Table 4 shows the predicted peak voltages for a controller with $T_{I}=40, K_{P}=27$. The deviation (overshoot) of the peak battery voltage from the set point $(14 \mathrm{~V})$ is approximately zero. This means that the disturbance is completely rejected.

\subsection{Controller tests}

The first test was conducted using an artificial current input (from a current-source ABM 9306 DUAL-TRACKING power supply) to the battery (YUASA-NP 38-12) to simulate the variation in solar power generation. The voltage was measured by the PIC microprocessor. The current was measured using a $0.003 \Omega$ resistor to convert the current into the voltage. Fig. 13 is the battery voltage variation under the charging current change (from $2 \mathrm{~A}$ to $5 \mathrm{~A}$ ), corresponding to the solar irradiation changing from $337 \mathrm{~W} / \mathrm{m}^{2}$ to $843 \mathrm{~W} / \mathrm{m}^{2}$.

The test starts at a battery voltage $14 \mathrm{~V}$ (set point) and the sampling rate is $0.01 \mathrm{~s}$. The result shows that the battery voltage rises to a maximum value of $14.1 \mathrm{~V}$ at about $0.62 \mathrm{~s}$, and then falls to $14.05 \mathrm{~V}$ after $0.9 \mathrm{~s}$. This shows that the control system can suppress the disturbance caused by a large sudden variation in solar radiation.

An outdoor test was then performed to test the real operation. An $85 \mathrm{Wp}$ flat-plate PV module (Table 5) with $2 \mathrm{X}$ reflective-type concentrator and YUASA-NP 38-12 lead-acid battery were used to test the control system performance. Fig. 14 shows the power generation of the PV module at ambient temperature $26 \pm 3{ }^{\circ} \mathrm{C}$. The PV voltage

Table 4

Peak voltage for $S_{o}$ changing from $300 \mathrm{~W} / \mathrm{m}^{2}$ to $900 \mathrm{~W} / \mathrm{m}_{2}\left(T_{I}=40\right.$, $\left.K_{P}=27\right)$.

\begin{tabular}{ll}
\hline & $\operatorname{Max} V_{B}(\mathrm{~V})$ \\
\hline Average model & 14.0075 \\
Model at operating point 1 & 14.0078 \\
Model at operating point 5 & 14.0047 \\
Model at operating point 9 & 14.0034 \\
\hline
\end{tabular}

Table 5

Specification of $85 \mathrm{Wp} \mathrm{PV} \mathrm{module} \mathrm{rated} \mathrm{at} 1000 \mathrm{~W} / \mathrm{m}^{2}$ irradiation and $25^{\circ} \mathrm{C}$ cell temperature.

\begin{tabular}{ll}
\hline Module name & F-MSN-85W-R02 \\
\hline Open circuit voltage, $V_{O C}$ & $21.34 \mathrm{~V}$ \\
Short circuit current, $I_{S C}$ & $5.697 \mathrm{~A}$ \\
MPP power, $P_{M A X}$ & $81.7 \mathrm{Wp}$ \\
MPP voltage, $V_{P M}$ & $16.43 \mathrm{~V}$ \\
MPP current, $I_{P M}$ & $4.99 \mathrm{~A}$ \\
\hline
\end{tabular}

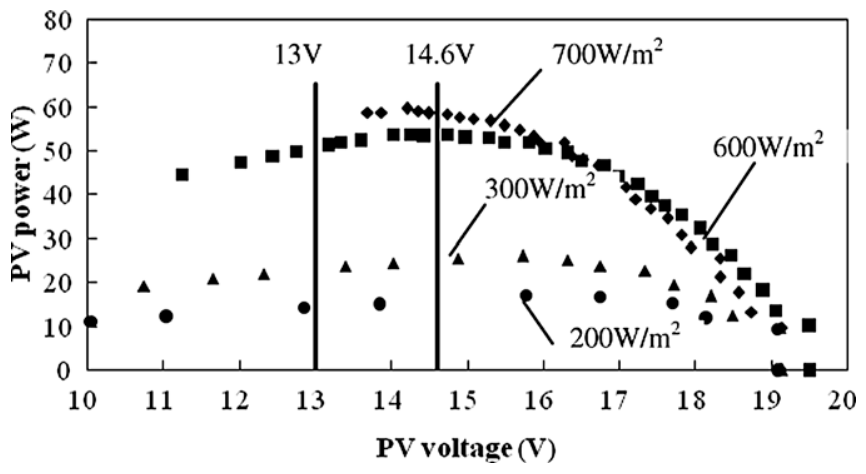

Fig. 14. Power generation of the PV module.

between the two vertical lines (13-14.6 V) also represents the operation voltage range of the lead-acid battery.

Fig. 15 is the test results of the outdoor system performance. The voltage and the current were measured by the PIC microprocessor mentioned previously. The sampling interval is $5 \mathrm{~min}$. It is seen that after the overcharge point, the mean charging current is reduced automatically. The battery voltage was basically kept at around $14 \mathrm{~V}$ (the set point) and there is a slight voltage fluctuation around $14 \mathrm{~V}$ due to measurement noise. The current started to decrease at $11 \mathrm{AM}$ when the solar radiation intensity was still increasing. It is seen that the feedback control system work very well. The test results show that the battery voltage never exceeds $14.1 \mathrm{~V}$ (less than the worst-case maximum voltage $14.4 \mathrm{~V}$ ). This indicates that the control system can continue charging and protect the battery from overcharge as well. The PV module ceased to charge the battery around 14:40 PM and the voltage reduced in Phase 3 , as seen from Fig. 15. From the test results of Fig. 16, it is seen that the charged energy at battery voltage up to $14 \mathrm{~V}$ is 59.6 Wh. The present PWM charging control system can keep the battery voltage at $14 \mathrm{~V}$ and continue charging 46.6 Wh more, after the overcharge point. That is, the charged energy of the battery increases $78 \%$, compared to the case that the charging stops after the overcharge point $(14 \mathrm{~V})$. This might happen very often for the battery operating at high SOC condition during clear days.

\subsection{Long-term outdoor test}

A long-term outdoor field test was carried out in the present study for a solar LED lighting systems consisting 


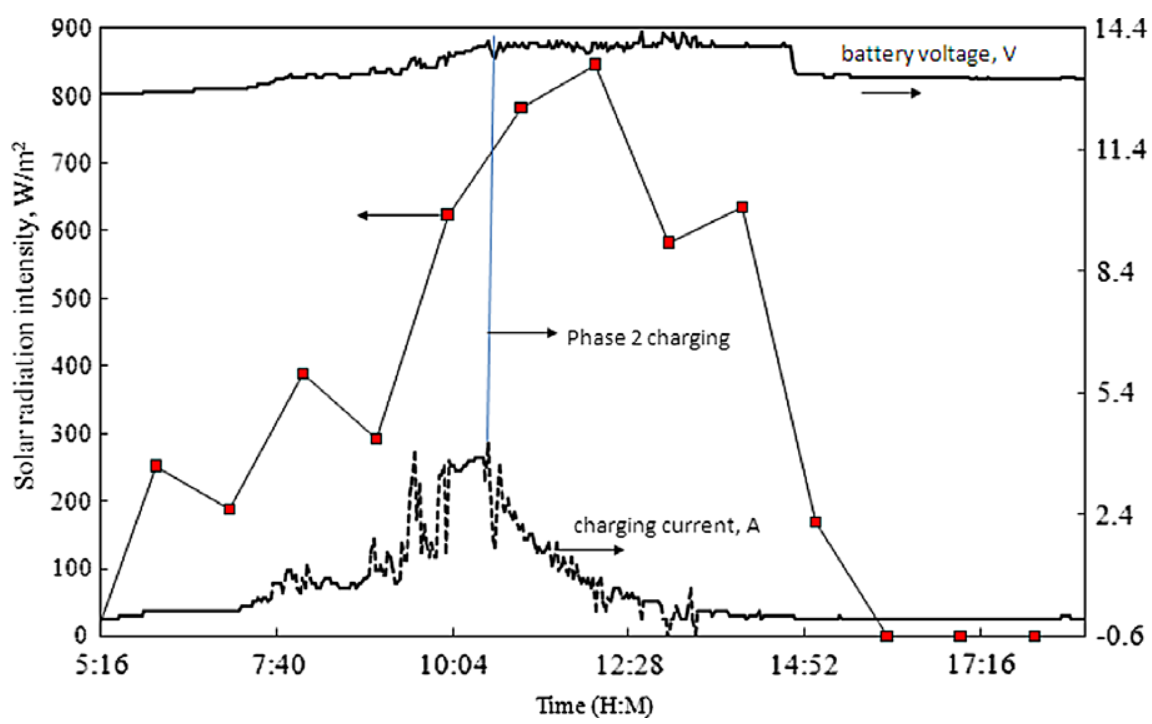

Fig. 15. Outdoor test of the battery charging control system (2008/06/28).

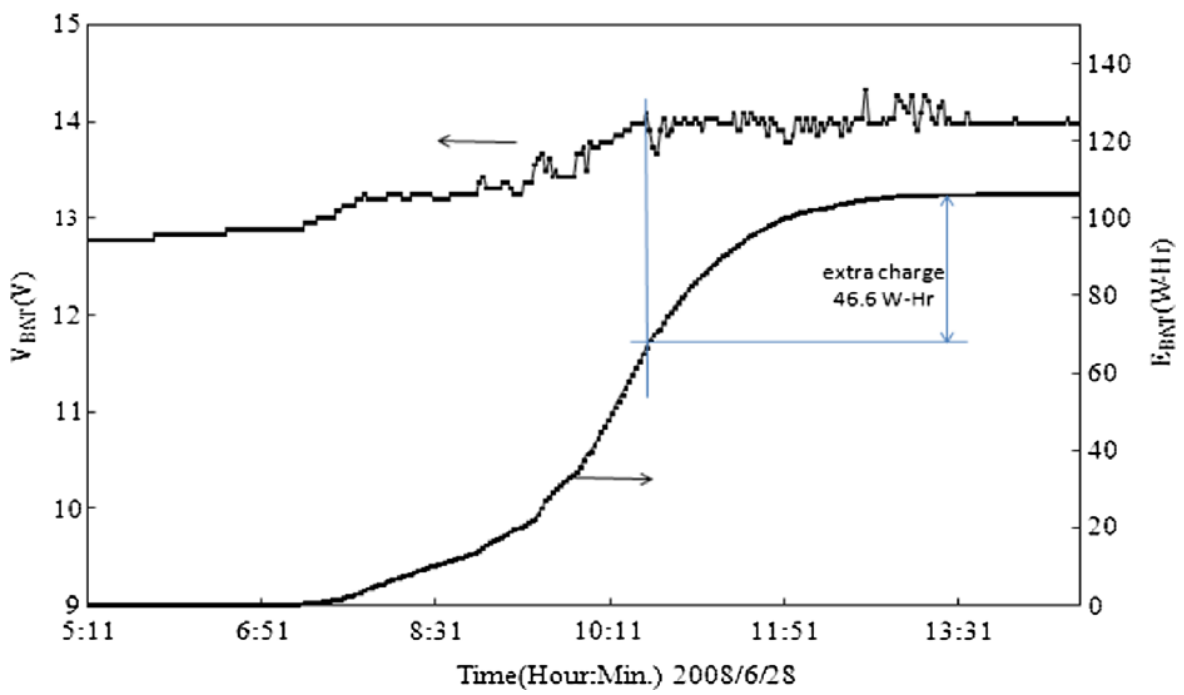

Fig. 16. Measured increase of battery charging capacity in outdoor test (2008/06/28).

of an $85 \mathrm{Wp}$ flat-plate PV module (Table 5) with a $2 \mathrm{X}$ reflective-type concentrator (Fig. 8), a YUASA-NP 38-12 lead-acid battery ( $12 \mathrm{~V} / 38 \mathrm{Ah})$, and a $18 \mathrm{~W}$ LED luminaire as the load for lighting at night. The solar charge/discharge controller was used. The controller will disconnect the load (LED) when the discharge voltage is below $11.3 \mathrm{~V}$.

The solar LED system test was carried out outdoor from May 23 to October 2 in 2008 to test the control system performance in summer. Fig. 17 shows that the battery voltage did not exceed $14.4 \mathrm{~V}$ at all. The control system is able to completely prevent the battery from overcharging in the summer. The lowest voltage never below $11.4 \mathrm{~V}$ which means that the energy charged to the battery during daytime is sufficient for the lighting of the $18 \mathrm{~W}$ LED luminaire at whole night.

The long-term test results of the solar LED lighting system show that the present battery charging control system can properly control the battery voltage to protect the battery from overcharging.

\section{Conclusion}

The lead-acid battery which is widely used in the standalone solar PV system is easily be damaged by a poor charging control which causes overcharging. To avoid overcharge, the battery is usually designed to stop charging at overcharge point and not to take a full-capacity charge. This will reduce the storage capacity and reduce the service time in electricity supply. A good charging control is thus very important. The design of control system however requires a good understanding of the system dynamic behaviour of the battery. In the present study, a first-order system dynamics model of lead-acid battery for different operating points near the overcharge voltage was derived 


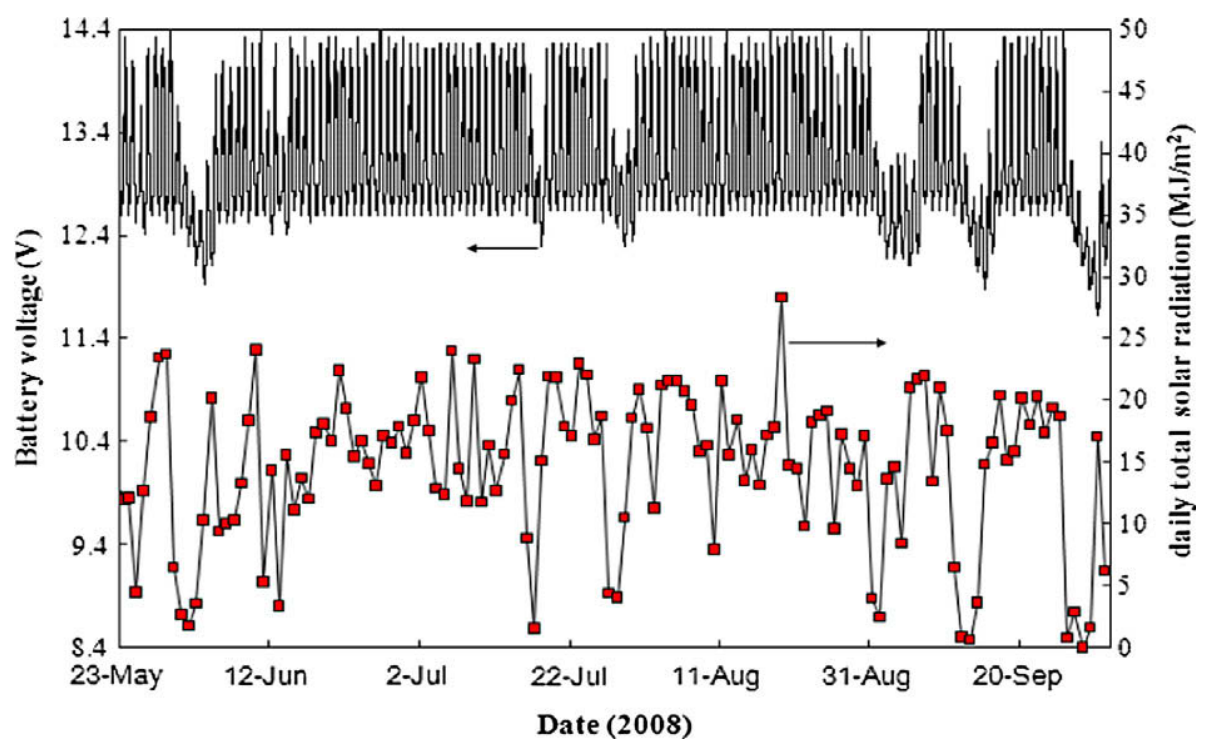

Fig. 17. Long-term test results of the solar LED lighting system (2008).

experimentally, from which a charging control system based on PI controller was developed using PWM technique. An outdoor field test for a solar-powered LED lighting system was then carried out to evaluate the long-term performance.

A feedback control system using PI algorithm was designed to compromise between the set-point response and the disturbance rejection. The experimental results show that the control system can suppress the battery voltage rising within $0.1 \mathrm{~V}$ when the solar irradiation is suddenly changed from $337 \mathrm{~W} / \mathrm{m}^{2}$ to $843 \mathrm{~W} / \mathrm{m}^{2}$. The outdoor test and the long-term tests shows that the battery voltage never exceeded $14.1 \mathrm{~V}$ and the control system can prevent the battery from overcharging. The long-term outdoor test results also show that the control system developed in the present study can control the battery never exceed $14.4 \mathrm{~V}$ and prevent from overcharge. The present battery charge control system using PWM technique does not use any sophisticated electrical circuit, further reducing the cost of the system and increasing its reliability. It is also shown that the PWM battery charge control technique can prevent the battery from overcharging and able to increase the charge capacity by $78 \%$, as compared to the case that the charging stops after the overcharge point $(14 \mathrm{~V})$. This might happen very often for the battery operating at high SOC condition during clear days.

\section{Acknowledgments}

This publication is based on work supported in part by Award No. KUK-C1-014-12, granted by King Abdullah University of Science and Technology (KAUST) and
Project No. 97-D0137-1, provided by the Energy Bureau, Ministry of Economic Affairs, Taiwan.

\section{References}

K.J. Åström, T. Hägglund T, 1995. PID controllers, 2nd ed. Research Triangle Park.

Berenguel, M., Camacho, E.F., Garcia-Maritin, F.J., Rubio, F.R., 1999. Temperature control of a solar furnace. IEEE Control Syst. Mag. 19 (1), 8-24.

Buller, S., Thele, M., Karden, E., Rik, W., De Doncker, 2003. Impedancebased non-linear dynamic battery modeling for automotive applications. J. Power Sources 113, 422-430.

Ceraolo, M., 2000. New dynamical models of lead-acid batteries. IEEE Trans. Power Syst. 15 (4), 1184-1190.

Ekdunge, P., 1993. A simplified model of the lead/acid battery. J. Power Sources 46, 251-262.

Jossen, A., Garche, J., Sauer, D.U., 2004. Operation conditions of batteries in PV applications. Solar Energy 76, 759-769.

Kim, S.C., Hong, W.H., 1999. Analysis of the discharge performance of a flooded lead/acid cell using mathematical modeling. J. Power Sources 77, 74-82.

Mauracher, P., Karden, E., 1997. Dynamic modeling of lead/acid batteries using impedance spectroscopy for parameter identification. J. Power Sources 67, 69-84.

Rake, H., 1980. Step response and frequency response methods. Automatica $16,519-526$.

Sabatier, J., Aoun, M., Oustaloup, A., Grégoire, G., Ragot, F., Roy, P., 2006. Fractional system identification for lead acid battery state of charge estimation. Signal Processing 86 (10), 2645-2657.

Shepherd, C.M., 1965. Design of primary and secondary cells. II. An equation describing battery discharge. J. Electrochem. Soc. 122 (7), 123.

Thele, M., Karden, E., Surewaard, E., Sauer, D.U., 2006. Impedancebased overcharging and gassing model for VRLA/AGM batteries. J. Power Sources 158, 953-963. 